\title{
Anterior Hip Dislocation After Hip Arthroscopy Complicated by Iliopsoas Bursitis
}

\author{
Matthew H. Nasra ${ }^{1}$, Christopher R. Michel ${ }^{2}$, Suleiman Sudah ${ }^{2}$, Christopher Dijanic ${ }^{2}$, Brian Torpey ${ }^{2}$ \\ 1. Orthopedic Surgery, Rutgers Robert Wood Johnson Medical School, New Brunswick, USA 2. Orthopedic Surgery, \\ Monmouth Medical Center, Long Branch, USA
}

Corresponding author: Matthew H. Nasra, mattnasra24@gmail.com

\begin{abstract}
Hip dislocation after hip arthroscopy is an uncommon postoperative complication. We report a case of a 51year-old woman who underwent right hip arthroscopy and presented with an anterior hip dislocation on postoperative day five. The index surgery involved capsulotomy, cam lesion debridement, and femoroplasty for an anterosuperior labral tear and cam-type femoroacetabular impingement. The patient underwent an uneventful recovery course until eight weeks postoperatively she developed iliopsoas bursitis. Her symptoms were managed conservatively with activity modification and physical rehabilitation. Complete resolution of symptoms was reported by the six-month follow-up visit, and no further dislocations or instability had been reported at 12 months. Anterior hip dislocation is a rare complication following hip arthroscopy and patients may experience persistent iliopsoas bursitis several months following successful reduction.
\end{abstract}

Categories: Orthopedics

Keywords: dislocation, arthroscopy, bursitis, hip, iliopsoas

\section{Introduction}

Hip arthroscopy (HA) is a surgical procedure increasing in popularity in recent years due to its relatively low complication rate and less invasive approach compared to traditional hip surgery [1,2]. Hip dislocation after HA is an infrequent complication [3-13]. Here, we report a case of an anterior hip dislocation occurring on a postoperative day five following capsulotomy, cam lesion debridement, and femoroplasty for an anterosuperior labral tear and cam-type femoroacetabular impingement (FAI). This case is unique as it is one of the first to report a dislocation in the acute postoperative period that had an association with persistent iliopsoas bursitis several weeks after successful closed reduction.

Review began 07/21/2021 Review ended 07/31/2021 Published 08/10/2021

๑) Copyright 2021

Nasra et al. This is an open access article distributed under the terms of the Creative Commons Attribution License CC-BY 4.0., which permits unrestricted use, distribution, and reproduction in any medium, provided the original author and source are credited.

\section{Case Presentation}

The patient is a 51-year-old woman who underwent right hip arthroscopy with labral repair and femoroplasty with cam lesion debridement. After failing years of conservative management for unremitting right hip and groin pain, she elected to undergo right hip arthroscopy. Following surgery, she was made partially weight-bearing with an early range of motion to assist in recovery. She experienced an uneventful postoperative course until day five. While cleaning her kitchen, she extended and externally rotated her operative leg resulting in sudden and severe right hip pain accompanied by a fall to the ground and an inability to bear weight.

Upon presentation, her right leg was shortened and externally rotated with intact neurovascular function. Radiographs revealed right anterior hip dislocation without evidence of acute fracture (Figure 1). 


\section{Cureus}

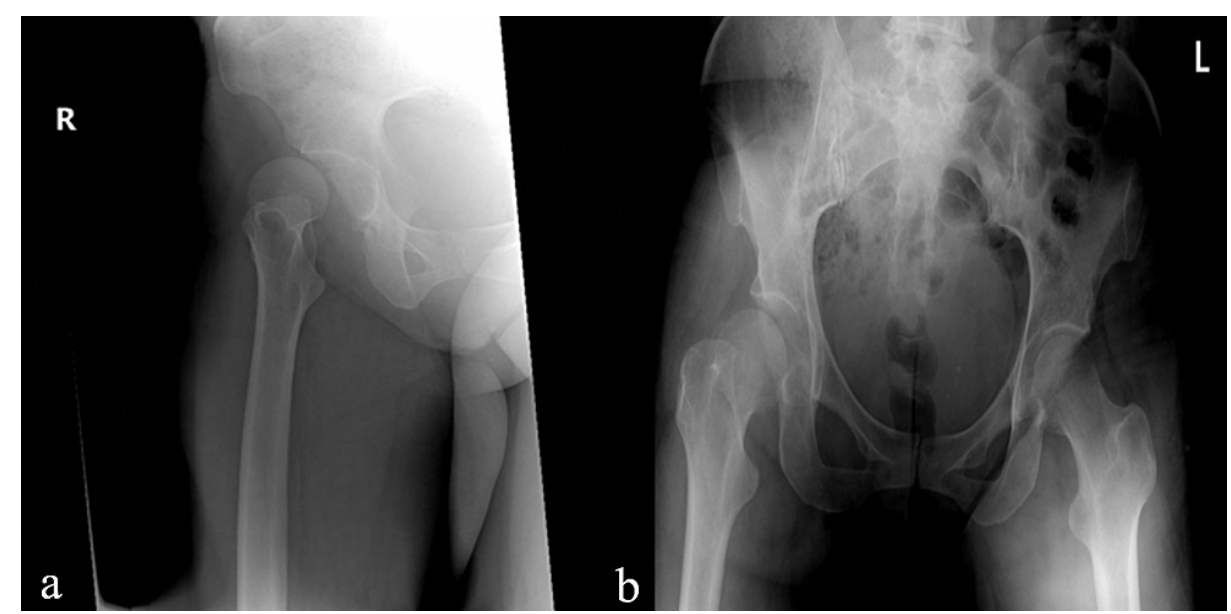

FIGURE 1: Radiographs of the right hip and pelvis showing anterior hip dislocation.

(a) Anteroposterior (AP) view of the right hip. The radiograph demonstrates that the femoral head has dislocated from the acetabulum in an anterior direction. (b) AP view of the right pelvis. This radiograph also shows that the right femoral head is dislocated compared to the contralateral side.

She was consciously sedated, closed reduced, and placed in a knee immobilizer (Figure 2).

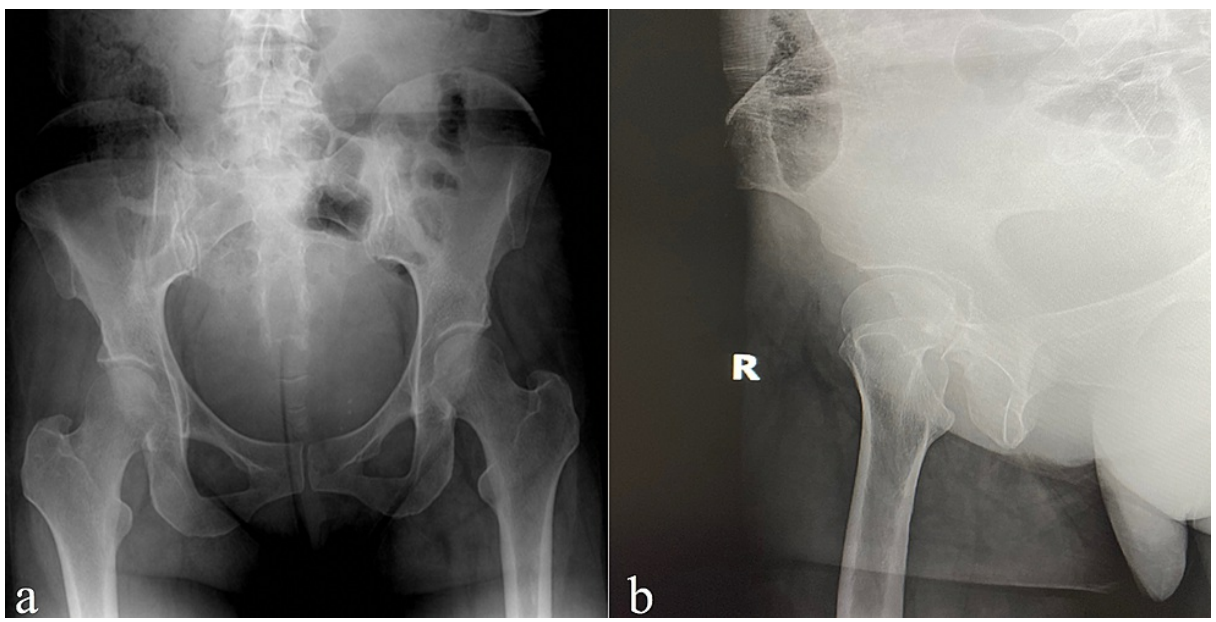

FIGURE 2: Radiographs of the right hip and pelvis postreduction.

(a) Anteroposterior (AP) view of the right pelvis and (b) lateral view of the right hip. These images show a wellreduced right hip joint with the femoral head and acetabulum in appropriate alignment.

Postreduction computed tomography (CT) revealed an impaction-type fracture in the anterior aspect of the femoral head (Figure 3). 


\section{Cureus}

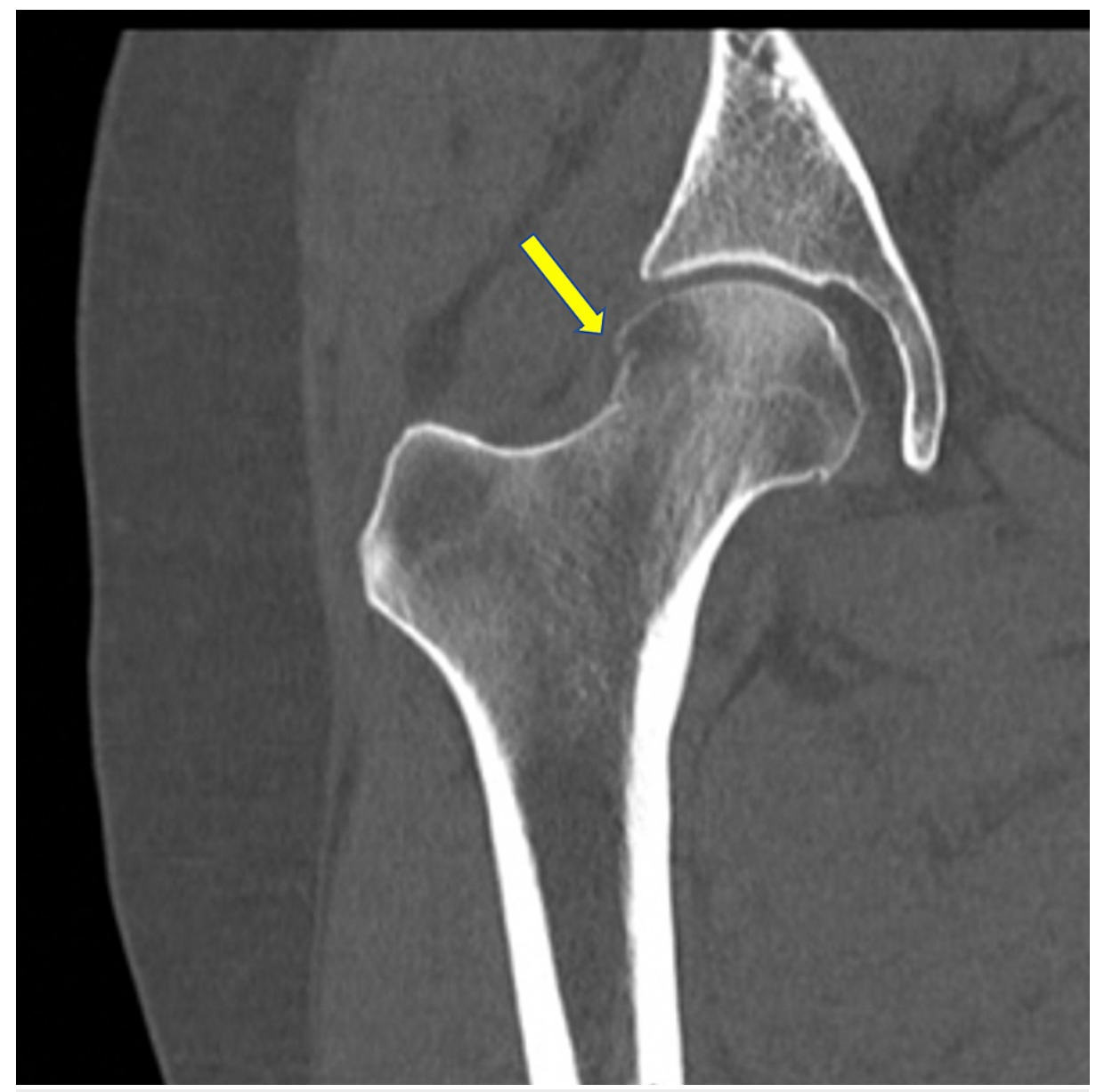

FIGURE 3: CT of the right hip.

Cortical step-off (yellow arrow) suspicious for impaction-type fracture in the anterior aspect of the femoral head.

Magnetic resonance imaging (MRI) was also obtained, which revealed an impaction fracture involving the anterior margin of the right femoral head and neck junction (Figure 4). 


\section{Cureus}

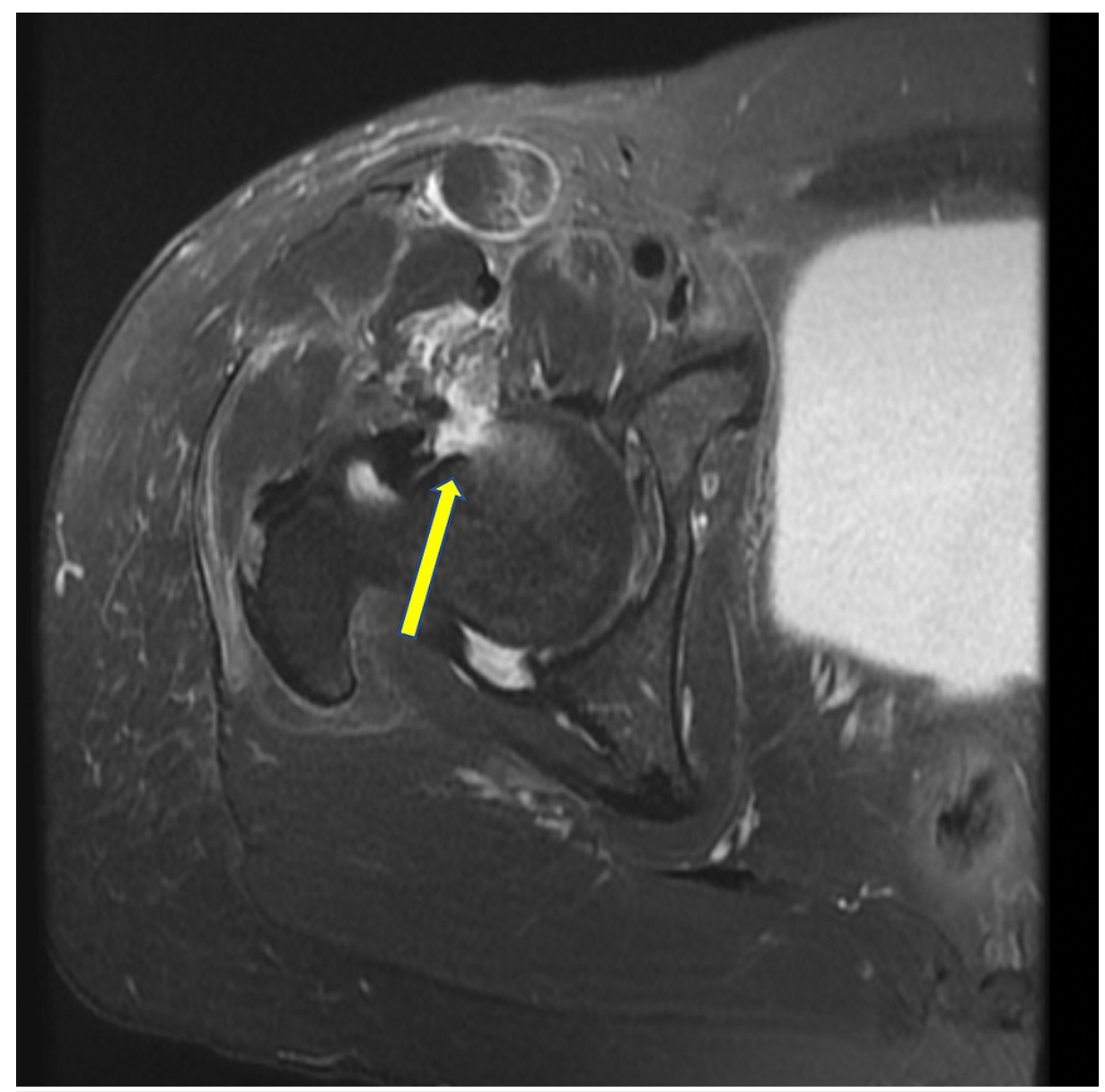

\section{FIGURE 4: MRI of the right hip.}

T2-axial fat-suppressed view demonstrates edema-like signal in the anterior femoral head and neck junction suggestive of impaction fracture (yellow arrow).

Surgical pathology of the cam resection and femoroplasty ruled out the presence of bony pathology. By one week postoperatively, she was able to ambulate with a walker. Physical examination revealed painless hip flexion greater than 100 degrees, extension to neutral, internal rotation to 35 degrees, and abduction to 45 degrees. However, she still experienced a sensation of anterior hip popping and had crepitus anteriorly. Initial MRI and CT scan were re-reviewed, and the labral repair appeared to be intact. She was advised to limit external rotation and hyperextension of the hip with protected weight-bearing and crutch use.

By six weeks postoperatively, her preoperative anterior hip popping and crepitus had entirely resolved. She experienced no pain in the anterior hip capsule and no apprehension with hyperextension or external rotation. The patient had a stable gait without the use of assistive devices and was able to perform a full crouch without difficulty.

The patient did not remain symptom-free during her continued follow-up visit. By eight weeks postoperatively, she experienced a re-intensification of her right hip pain that she characterized as a deep ache in the joint. Her hip occasionally locked and was accompanied by a sense of instability. She denied a history of trauma - other than the recent hip dislocation - or inciting events. Physical examination revealed palpable crepitus in the anterior acetabular margin at 60 degrees to 90 degrees of flexion. Both internal and external rotation aggravated these symptoms. The patient could ambulate, although she preferred to take small steps with her right lower extremity to reduce pain. Radiographs of the right hip revealed a wellmaintained joint surface and joint line architecture with no gross bony abnormalities.

Subsequent MRI revealed right iliopsoas bursitis with filling defects in the joint recesses and the iliopsoas bursa suspicious for synovial proliferation and small intra-articular bodies (Figure 5). 


\section{Cureus}

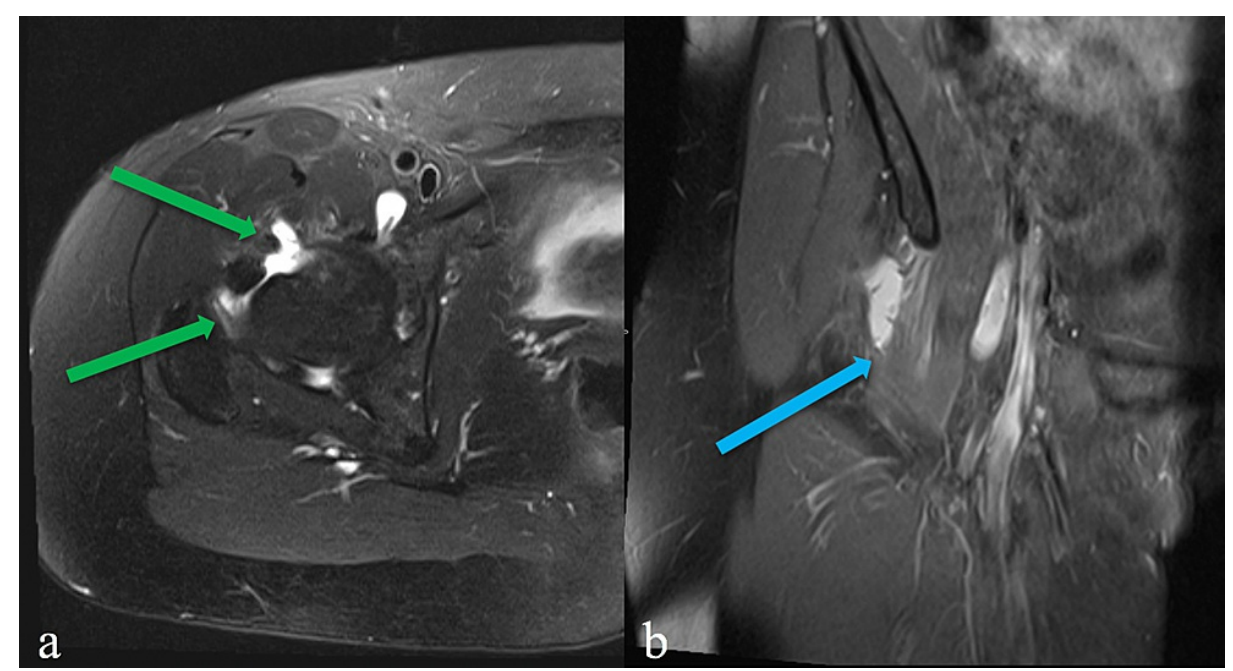

FIGURE 5: MRI of the right hip.

(a) T2-axial fat-suppressed. Filling defects in the joint recesses and the iliopsoas bursa suspicious for synovial proliferation and small intra-articular bodies (green arrows). (b) Coronal proton-density (PD). Edemalike signal in the right iliopsoas muscle (blue arrow) compatible with tendinosis/tendinopathy and fluid in the iliopsoas bursa.

Additionally, new-onset small focal cartilage loss and osteochondral impaction injury in the femoral head secondary to microtrauma and instability were identified. Her symptoms were managed conservatively with activity modification and physical rehabilitation. Complete resolution of symptoms was reported by a sixmonth follow-up, and no further dislocations or instability had been reported at 12 months.

\section{Discussion}

HA is a low-risk, minimally invasive procedure with numerous indications, including acetabular labral tears, FAI, chondral lesions, osteochondritis dissecans, ligamentum teres injuries, snapping hip syndrome, iliopsoas bursitis, and loose bodies [2]. Hip arthroscopy is an appealing procedure to surgeons due to its low rate of major complications. A systematic analysis by Harris et al. revealed that iatrogenic chondrolabral injury is the most common complication of HA, with hip dislocations occurring far less frequently [14]. In particular, hip dislocations accounted for four out of the 6134 cases examined in their study

[14]. Additionally, Larson et al. reported no cases of iatrogenic hip instability in 1026 arthroscopies reviewed [15].

With such an exceedingly low complication rate, post arthroscopic hip dislocation has not been well documented. The majority of cases of hip dislocation after HA reported have been anterior hip dislocations [3-13]. Alternatively, in the general population, anterior hip dislocations happen far less frequently than posterior dislocations [16]. Several surgical risk factors during hip arthroscopy are thought to contribute to post arthroscopic hip instability. These include failure to repair the capsule, iliopsoas debridement and tenotomy, cam resection, and partial psoas release [4]. While the surgical technique is crucial for success, it is equally important to identify contributing patient risk factors. Patient risk factors that increase the risk of dislocation following HA include female gender, ligamentous laxity, connective tissue disease, acetabular dysplasia, femoral anteversion greater than 40 degrees, a center-edge angle of fewer than 25 degrees, and an increased capsular volume [17,18].

Our patient underwent a transverse limb capsulotomy of the anterior joint capsule without repair, rim trimming of the acetabular margin, and femoroplasty with cam lesion resection. Interestingly, our patient experienced anterior hip dislocation only five days post arthroscopy. The patient also sustained a femoral head fracture, intra-articular loose bodies, and focal cartilage loss that resulted from the original injury. We can postulate from our experience that intraoperative distension and stretching of the anterior joint capsule may create instability and thus the risk for dislocation and subsequent injuries. Prior studies reported dislocation events that occurred immediately in the recovery room [6], on postoperative day one [13], three weeks postoperatively [10], and the remaining between two and seven months [4,7-9,11,12].

Inciting mechanisms vary depending on the activity level of the individual. Less active individuals frequently report a low energy twist or fall $[7,10,11]$. Alternatively, more active individuals report participation in higher energy events such as long jumping [9], javelin throwing [8], running [8], or ballet dancing [12]. While these vary drastically, they all have a common component of hip extension and external rotation, which was also present in our case. 
Our patient was diagnosed with new-onset iliopsoas bursitis eight weeks following closed reduction of her post arthroscopic anterior hip dislocation. Six other cases describe further complications that required additional surgery: residual pain and apprehension treated with arthroscopic capsular plication [7], gross hip instability treated with mini-open capsular repair [6], severe instability treated with total hip arthroplasty [13], persistent instability treated with revision open capsulorrhaphy [11], persistent instability treated with capsular reconstruction [12], and progressive end-stage arthritis treated with total hip arthroplasty [10]. The remaining cases discuss patients who experienced a baseline return to function with no long-term complications $[8,9]$.

\section{Conclusions}

Anterior hip dislocation after HA is an uncommon postoperative complication of an otherwise safe and wellregarded procedure. Surgeons must be aware of the surgical and patient-specific risk factors that contribute to postoperative hip instability in order to optimize patient safety in both the acute and chronic stages of recovery. Furthermore, the presence of iliopsoas bursitis, degenerative arthritis, and other causes of continued hip pain following closed hip reduction is an important topic that requires further investigation as the incidence of these complications is likely to rise with a growing number of hip arthroscopy procedures. This case emphasizes the need to investigate safer techniques to minimize postoperative complications, avoid dislocation after hip arthroscopy, and successfully manage resulting pathology.

\section{Additional Information}

\section{Disclosures}

Human subjects: Consent was obtained or waived by all participants in this study. Conflicts of interest: In compliance with the ICMJE uniform disclosure form, all authors declare the following: Payment/services info: All authors have declared that no financial support was received from any organization for the submitted work. Financial relationships: All authors have declared that they have no financial relationships at present or within the previous three years with any organizations that might have an interest in the submitted work. Other relationships: All authors have declared that there are no other relationships or activities that could appear to have influenced the submitted work.

\section{References}

1. Colvin AC, Harrast J, Harner C: Trends in hip arthroscopy. J Bone Joint Surg Am. 2012, 94:23. 10.2106/JBJS.J.01886

2. Shetty VD, Villar RN: Hip arthroscopy: current concepts and review of literature. Br J Sports Med. 2007, 41:64-8. 10.1136/bjsm.2006.027755

3. Duplantier NL, McCulloch PC, Nho SJ, Mather RC 3rd, Lewis BD, Harris JD: Hip dislocation or subluxation after hip arthroscopy: a systematic review. Arthroscopy. 2016, 32:1428-34. 10.1016/j.arthro.2016.01.056

4. Yeung M, Memon M, Simunovic N, Belzile E, Philippon MJ, Ayeni OR: Gross instability after hip arthroscopy: an analysis of case reports evaluating surgical and patient factors. Arthroscopy. 2016, 32:11961204. 10.1016/j.arthro.2016.01.011

5. Rosenbaum A, Roberts T, Flaherty M, Phillips N, Patel N, Das P: Posterior dislocation of the hip following arthroscopy - a case report and discussion. Bull Hosp Jt Dis. 2014, 72:181-4.

6. Matsuda DK: Acute iatrogenic dislocation following hip impingement arthroscopic surgery. Arthroscopy. 2009, 25:400-4. 10.1016/j.arthro.2008.12.011

7. Ranawat AS, McClincy M, Sekiya JK: Anterior dislocation of the hip after arthroscopy in a patient with capsular laxity of the hip. a case report. J Bone Joint Surg Am. 2009, 91:192-7. 10.2106/JBJS.G.01367

8. Sansone M, Ahldén M, Jónasson P, Swärd L, Eriksson T, Karlsson J: Total dislocation of the hip joint after arthroscopy and ileopsoas tenotomy. Knee Surg Sports Traumatol Arthrosc. 2013, 21:420-3. 10.1007/s00167012-2300-3

9. Austin DC, Horneff JG 3rd, Kelly JD 4th: Anterior hip dislocation 5 months after hip arthroscopy. Arthroscopy. 2014, 30:1380-2. 10.1016/j.arthro.2014.04.099

10. Wylie JD, Beckmann JT, Aoki SK: Dislocation after hip arthroscopy for cam-type femoroacetabular impingement leading to progressive arthritis: a case report. JBJS Case Connect. 2015, 5:80-7. 10.2106/JBJS.CC.N.00150

11. Dierckman BD, Guanche CA: Anterior hip capsuloligamentous reconstruction for recurrent instability after hip arthroscopy. Am J Orthop. 2014, 43:319-23.

12. Yeung M, Khan M, Williams D, Ayeni OR: Anterior hip capsuloligamentous reconstruction with Achilles allograft following gross hip instability post-arthroscopy. Knee Surg Sports Traumatol Arthrosc. 2017, 25:38. 10.1007/s00167-016-4258-z

13. Souza BG, Dani WS, Honda EK, Ricioli W Jr, Guimarães RP, Ono NK, Polesello GC: Do complications in hip arthroscopy change with experience?. Arthroscopy. 2010, 26:1053-7. 10.1016/j.arthro.2009.12.021

14. Harris JD, McCormick FM, Abrams GD, et al.: Complications and reoperations during and after hip arthroscopy: a systematic review of 92 studies and more than 6,000 patients. Arthroscopy. 2013, 29:589-95. 10.1016/j.arthro.2012.11.003

15. Larson CM, Clohisy JC, Beaulé PE, Kelly BT, Giveans MR, Stone RM, Samuelson KM: Intraoperative and early postoperative complications after hip arthroscopic surgery: a prospective multicenter trial utilizing a validated grading scheme. Am J Sports Med. 2016, 44:2292-8. 10.1177/0363546516650885

16. Foulk DM, Mullis BH: Hip dislocation: evaluation and management . J Am Acad Orthop Surg. 2010, 18:199209. 10.5435/00124635-201004000-00003

17. Kraeutler MJ, Garabekyan T, Pascual-Garrido C, Mei-Dan O: Hip instability: a review of hip dysplasia and 


\section{Cureus}

other contributing factors. Muscles Ligaments Tendons J. 2016, 6:343-53. 10.11138/mltj/2016.6.3.343

18. Wylie JD, Beckmann JT, Maak TG, Aoki SK: Arthroscopic capsular repair for symptomatic hip instability after previous hip arthroscopic surgery. Am J Sports Med. 2016, 44:39-45. 10.1177/0363546515608162 